\title{
PENGARUH LITERASI KEUANGAN DAN FAKTOR DEMOGRAFI TERHADAP MINAT INVESTASI MAHASISWA
}

\author{
Oleh: \\ Faridhatun Faidah \\ Program Studi Manajemen, Fakultas Ekonomi dan Bisnis \\ Universitas Muria Kudus \\ Email: \\ faridhatun.faidah@umk.ac.id
}

\begin{abstract}
ABSTRAK
Tujuan dari penelitian ini adalah untuk menganalisis pengaruh antara faktor demografik (tahun masuk, IPK dan pendapatan mahasiswa) dan literasi keuangan terhadap minat investasi mahasiswa pada Fakultas Ekonomi dan Bisnis di Universitas Muria kudus. Penelitian ini menggunakan metode kualitatif dengan sampel sebanyak 90 mahasiswa yang dipilih secara random dari angkatan 20142018. Metode penelitian yang digunakan menggunakan analisis regresi berganda dengan bantuan program SPSS 20. Hasil penelitian ini menunjukkan bahwa terdapat pengaruh positif signifikan antara variabel literasi keuangan dan faktor demografi terhadap minat investasi mahasiswa baik secara parsial maupun simultan. Hal tersebut berarti bahwa semakin baik literasi keuangan yang dimiliki mahasiswa dapat meningkatkan minat investasi. Selain itu faktor demografi berupa tahun masuk mahasiswa, nilai Indeks prestasi mahasiswa dan juga pendapatan yang semakin tinggi juga dapat meningkatkan minat investasi mahasiswa.
\end{abstract}

Kata Kunci: Literasi Keuangan, Faktor Demografi, Investasi

\begin{abstract}
The purpose of this study was to analyze the influence of demographic factors (year of entry, GPA and student income) and financial literacy on student investment decision in the Faculty of Economics and Business at Muria Kudus University. This study used a qualitative method with a sample of 90 students randomly selected from the 2014-2018 class. The research method uses multiple regression analysis with the help of SPSS 20. The results of this study indicate that there is significant positive influence between financial literacy variables and demographic factors on student investment decision both partially and simultaneously. This means that the better financial literacy that students have can increase investment decision. In addition, demographic factors such as the year of entry of students, the value of Grade Point Average (GPA) as well as higher income can also increase student investment decision.
\end{abstract}

Keyword: Financial Literacy, Demographic Factors, Investment 


\section{A. PENDAHULUAN}

Seiring berkembangnya era modern saat ini yang diikuti pula oleh perkembangan produk keuangan yang semakin komplek menjadikan pengambilan keputusan keuangan yang baik menjadi penting untuk bisa diperhatikan oleh semua orang. Selain itu seseorang juga membutuhkan untuk menyisihkan sebagian pendapatannya dalam tabungan sebagai dana persiapan ketika pensiun. Dari sini perlu adanya literasi keuangan yang dapat membantu seseorang dalam melakukan perencanaan dan juga pengambilan keputusan keuangan yang baik agar dapat mencapai tujuan yang ingin dicapai yaitu kesejahteraan financial di masa yang akan datang.

Hasil penelitian Cheung et al (2015) menyatakan bahwa tingkat literasi keuangan yang rendah menjadi penyebab dari timbulnya masalah keuangan. Literasi keuangan yang dimaksud disini yaitu pengetahuan yang dimiliki oleh seseorang terkait dengan adanya lembaga keuangan baik jenis produk yang dikeluarkannya maupun keuntungan dan kerugian yang mungkin muncul dari produk tersebut. Selain mengetahui jenis produk, seseorang dianggap sudah memiliki literasi keuangan yang baik apabila dia sudah mempunyai keahlian untuk memanfaatkan produk keuangan yang ditawarkan oleh lembaga keuangan. Lembaga keuangan disini mulai dari perbankan, asuransi, pegadaian, lembaga dana pensiun dan pasar modal.

Saat ini tingkat literasi keuangan pada penduduk Indonesia berdasarkan hasil survey Nasional Keuangan Indonesia pada tahun 2016 masih berada pada tingkat 29,66\%. Dimana literasi keuangan paling rendah dilihat dari sektor keuangan ada pada pasar modal. Tercatat survei OJK yang menunjukkan bahwa pada tahun 2016 literasi keuangan pada sektor pasar modal baru mencapat 4,40\%. Literasi yang rendah ini diikuti pula oleh masih rendahnya inklusi keuangan pada pasar modal yang baru mencapai 1,25\% di tahun 2016 .

Pasar modal memiliki peran yang sangat penting untuk meningkatkan perekonomian suatu Negara melalui beberapa fungsinya yang diantaranya yaitu sebagai sarana perusahaan untuk mencari modal usaha dan masyarakat yang memiliki kelebihan dana untuk dapat melakukan investasi. Untuk investasi di pasar modal, seseorang diwajibkan untuk dapat membuka akun di salah satu sekuritas efek yang terdaftar di Bursa Efek Indonesia agar dapat memperoleh Rekening Dana Nasabah (RDN). RDN inilah nantinya yang akan digunakan mahasiswa untuk dapat mengontrol transaksi yang dilakukan di dalam pasar modal. Materi tentang pasar modal dan lembaga keuangan lainnya biasanya sudah diajarkan di dalam perguruan tinggi karena masuk ke dalam mata kuliah yang harus diambil oleh mahasiswa. Oleh karena itu, mahasiswa disini dianggap sudah mendapatkan literasi keuangan dan sudah seharusnya untuk dapat menambah inklusi keuangan yang ada di Indonesia termasuk untuk melakukan investasi.

Literasi keuangan dapat terbentuk dari proses pembelajaran yang diterapkan di dalam suatu perguruan tinggi dan menurut Widayati (2012) hal ini akan berkontribusi banyak terhadap pengetahuan keuangan yang akan dimiliki oleh mahasiswa. Keputusan investasi disinilah yang menjadi fokus perhatian dalam penelitian ini dimana ada banyak faktor yang dapat mempengaruhinya. Penelitian Margaretha (2015) menunjukkan bahwa IPK mahasiswa mempengaruhi minat 
investasi mereka. Hal ini berarti bahwa kemampuan akademik yang tergambarkan dalam nilai IPK mahasiswa belum menjamin literasi keuangan yang baik. Selain itu mahasiswa yang masuk ke universitas lebih dulu atau senior terbukti memiliki literasi keuangan lebih baik dibandingkan mahasiswa yunior yang baru masuk universitas. Hal ini dibuktikan oleh penelitian Shaari et al (2013) dimana tahun masuk mahasiswa berpengaruh positif terhadap literasi keuangan.

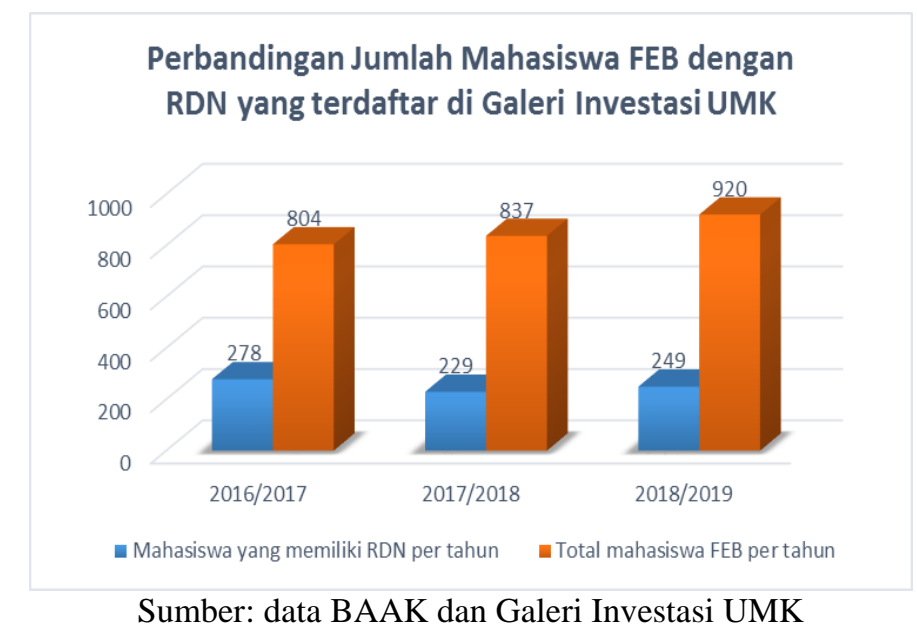

Gambar 1.

Data Jumlah Mahasiswa FEB UMK dengan Jumlah Rekening Dana
Nasabah yang Terdaftar di Galeri Investasi FEB UMK

Gambar 1 di atas adalah data perbandingan jumlah mahasiswa Fakultas Ekonomi dan Bisnis (FEB) di Universitas Muria Kudus (UMK) yang telah memiliki Rekening Dana Nasabah (RDN) dengan total mahasiswa FEB pada tiap tahunnya. Dapat dilihat pada gambar 1 tersebut bahwa total mahasiswa yang diterima di UMK dari tahun ke tahun mengalami kenaikan, namun tidak diikuti dengan kenaikan jumlah mahasiswa yang membuka RDN di Galeri Investasi FEB UMK. Hal tersebut dapat dilihat dari persentasi antara mahasiswa yang diterima dengan mahasiswa yang memutuskan untuk membuka RDN yaitu dimana pada tahun ajaran 2016/2017 adalah sebesar 34,58\% sedangkan pada tahun-tahun berikutnya yaitu tahun 2017/2018 dan 2018/2019 turun hanya sebesar 27,36\% dan $27.07 \%$.

Hasil dari gambar 1 di atas menunjukkan bahwa bertambahnya seseorang yang memiliki pengetahuan keuangan tidak dapat meningkatkan jumlah investasi. Hasil penelitian Herdjiono dan Damanik (2016) juga menyatakan bahwa literasi keuangan tidak berpengaruh terhadap keputusan investasi. Hasil penelitian Lusardi, A., \& Mitchell, O. (2011) yang menunjukkan bahwa tingkat literasi keuangan berpengaruh signifikan terhadap keputusan investasi. Dari sini muncul hasil penelitian dan data yang berbeda, sehingga disini penulis ingin melakukan penelitian kembali apakah faktor demografik dan literasi keuangan mempengaruhi minat investasi mahasiswa FEB UMK. 


\section{B. KAJIAN PUSTAKA}

\section{Investasi}

Seorang investor harus memiliki kemampuan menganalisis yang baik dan bijaksana dalam mengambil keputusan investasi (Investment Decision Making). Kemampuan ini menurut Farooq dan Sajid (2015) menjadi kegiatan tersulit yang harus dilakukan oleh investor sebelum memutuskan untuk berinvestasi. Investor dalam mengambil keputusan berinvestasi menurut Putra (2016) ada yang menggunakan sikap rasional (logika berfikir) namun terdapat juga yang secara irrasional (tidak masuk akal). Investasi adalah komitmen seseorang untuk menanamkan sebagian uang yang milikinya pada suatu aset tertentu dengan tujuan agar dapat memberikan keuntungan di masa depan. Investasi berdasarkan bentuknya dibedakan ke dalam dua bentuk yaitu investasi pada aset real (real assets) dan aset keuangan (financial assets). Investasi pada aset real dapat dilakukan dengan cara membeli emas, tanah, bangunan, mesin dan bentuk aset fisik lainnya yang nilainya akan bertambah di masa depan. Sedangkan untuk investasi pada aset keuangan dapat dilakukan dengan cara membeli saham, obligasi, deposito, reksadana dan produk keuangan lainnya.

\section{Literasi Keuangan}

Literasi keuangan (Financial Literacy) menurut Hogarth (2002) adalah cara bagaimana seseorang mengatur keuangan mereka dalam berasuransi, instasi, menabung dan melakukan penganggaran (budgeting). Menurut David (2010) literasi keuangan memiliki 5 poin utama yang terdiri dari 1) Pengetahuan tentang konsep keuangan 2) Kemampuan untuk berkomunikasi tentang konsep keuangan 3) Kemampuan untuk mengelola keuangan pribadi 4) Kemampuan dalam membuat keputusan keuangan 5) Keyakinan untuk membuat perencanaan keuangan masa depan. Menurut Servon \& Kaestner (2008) berkembangnya Literasi keuangan saat ini antara lain disebabkan oleh rendahnya suku bunga tabungan, banyak orang atau perusahaan yang bangkrut, jumlah prosentase pinjaman/utang, dan keharusan untuk individu dapat mempertanggungjawabkan keputusan yang telah dipilih karena akan sangat menentukan masa depan mereka.

Bhushan and Medury (2013) menyatakan bahwa penting untuk bisa memperoleh literasi keuangan dikarenakan saat ini banyak sekali produk keuangan yang mulai muncul dan seorang individu diharuskan untuk dapat mengerti risiko serta keuntungan dari produk keuangan tersebut. Dari literasi keuangan inilah Individu akan dapat menggunakan jasa dan produk keuangan secara benar sesuai dengan kebutuhan yang dia inginkan dan tidak mudah ditipu oleh oknum kejahatan yang sering memanfaatkan ketidaktahuan seseorang tentang keuangan untuk memperoleh keuntungan pribadi. Dari sinilah peran literasi keuangan muncul yaitu untuk membantu memperbaiki kualitas dari pelayanan keuangan agar semakin baik dan dapat berkontribusi menumbuhkan perekonomian serta pembangunan suatu negara. Allgood (2016) dari penelitian yang telah dilakukan juga menyatakan bahwa literasi keuangan mempengaruhi keputusan seseorang dalam melakukan investasi. 


\section{Faktor Demografi}

Faktor demografi disini dapat diukur dengan menggunakan banyak indikator yang diantaranya menurut Chen and Volpe (1998) tingkat kesenioran mahasiswa ikut mempengaruhi literasi keuangan yang dimiliki dimana mahasiswa dengan tahun masuk lebih dulu memiliki literasi keuangan yang lebih tinggi dibandingkan dengan mahasiswa yang baru masuk kuliah. Hasil tersebut sesuai dengan penelitian dari Shaari et al. (2013) yang menunjukkan bahwa tahun masuk kuliah mahasiswa ke perguruan tinggi berpengaruh positif terhadap literasi keuangan yang dimiliki mahasiswa.

Allgood, (2016) dan Mahdzan, N.S., \& Tabiani, S. (2013) di dalam penelitiannya menyatakan bahwa pendapatan seorang individu juga mempengaruhi secara positif signifikan terhadap keputusan investasi yang dilakukan. Hal ini berarti semakin tinggi pendapatan yang diperoleh seseorang maka minat investasinya juga akan semakin meningkat. Pendapatan pada mahasiswa diperoleh dari uang saku yang diberikan oleh orang tuanya dan beberapa dari hasil kerja part time atau sampingan mereka sendiri selama kuliah. Selain pendapatan, kemampuan akademik atau ability academic yang dimiliki oleh seseorang dalam hal ini adalah mahasiswa juga menjadi penentu dari dimilikinya literasi keuangan yang baik sehingga menambah minat investasi seseorang. Penelitian Cude et al. (2006) menunjukkan bahwa tingginya nilai IPK yang dimiliki mahasiswa mempengaruhi kondisi keuangan mereka menjadi lebih baik dan sehat. Hasil tersebut sesuai dengan Sabri et al. (2008) yang menyatakan bahwa mahasiswa dengan IPK tinggi memiliki permasalahan keuangan yang lebih sedikit dibandingkan mahasiswa yang memiliki IPK yang rendah.

\section{Hipotesis}

Berdasarkan tinjauan pustaka yang telas dijelaskan di atas, diperoleh hipotesis pada penelitian ini sebagai berikut:

$\mathrm{H}_{1}=$ Literasi Keuangan berpengaruh positif terhadap minat investasi mahasiswa FEB UMK

$\mathrm{H}_{2}=$ Faktor Demografi berpengaruh positif terhadap minat investasi mahasiswa FEB UMK

$\mathrm{H}_{3}=$ Literasi Keuangan dan Faktor Demografi berpengaruh secara simultan terhadap minat investasi mahasiswa FEB UMK

\section{METODE PENELITIAN}

Penelitian ini menggunakan teknik analisis regresi berganda yang dilakukan untuk melakukan pengujian pengaruh dari variabel independen terhadap variabel dependen baik secara parsial maupun simultan dengan menggunakan program SPSS 20. Teknik pengambilan sampel dalam penelitian ini menggunakan convenience sampling. Responden dalam penelitian ini adalah mahasiswa Fakultas Ekonomi dan Bisnis (FEB) di Universitas Muria Kudus (UMK) yaitu sebanyak 90 mahasiswa. Penentuan jumlah sampel tersebut mengacu pada pendapat (Sugiyono, 2017) yang menyatakan bahwa jumlah 
anggota sampel minimal adalah 10 kali dari jumlah variabel yang diteliti (independen + dependen). Berdasarkan ketentuan inilah yang membuat penulis menetapkan jumlah sampel sebanyak 30 kali dari jumlah variabel yang digunakan yaitu 3 variabel, sehingga dipilih sampel sebanyak 90. Pengumpulan data dilakukan dengan menggunakan angket/kuesioner yang dibagikan menggunakan google form kepada mahasiswa dari angkatan 2014-2018. Dalam penelitian ini, terdapat dua variabel independen yaitu literasi keuangan $\left(\mathrm{X}_{1}\right)$ dan faktor demografi $\left(\mathrm{X}_{2}\right)$. Sedangkan untuk variabel dependen yang digunakan yaitu minat investasi mahasiswa $\left(\mathrm{Y}_{1}\right)$. Hubungan antar variabel dapat digambarkan sebagai berikut:

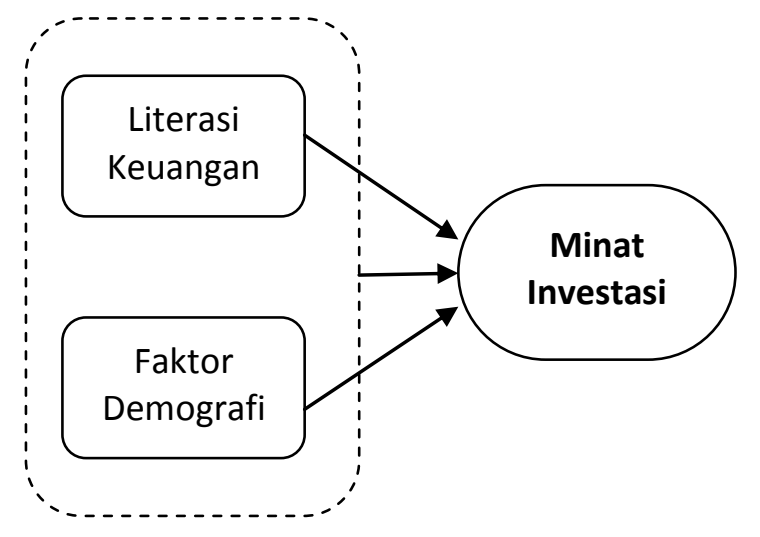

\section{Gambar 2.}

\section{Model Penelitian}

Berdasarkan model penelitian di atas, maka persamannya adalah sebagai berikut:

Dimana:

$$
\mathrm{Y}_{1}=\rho \mathrm{Y}_{1} \mathrm{X}_{1}+\rho \mathrm{Y}_{1} \mathrm{X}_{2}+\varepsilon_{1}
$$

$\mathrm{X}_{1}=$ Literasi Keuangan

$\mathrm{X}_{2}=$ Faktor Demografi

$\mathrm{Y}_{1}=$ Minat Investasi

\section{Indikator Variabel}

Variabel yang digunakan dalam penelitian ini adalah variabel literasi keuangan, faktor demografi dan minat investasi. Skala pengukuran yang digunakan untuk mengukur variabel penelitian adalah skala likert 1 sampai 5 . Indikator Indikator untuk mengukur variabel tersebut adalah: 
Tabel 1

Indikator Variabel

\begin{tabular}{|c|c|c|c|}
\hline VARIABEL & & INDIKATOR & SUMBER \\
\hline \multirow{2}{*}{$\begin{array}{l}\text { Literasi Keuangan } \\
\quad\left(\mathrm{X}_{1}\right)\end{array}$} & $\mathrm{X}_{1.1}$ & Konsep bunga (interest) & \\
\hline & $\begin{array}{l}\mathrm{X}_{1.2} \\
\mathrm{X}_{1.3}\end{array}$ & $\begin{array}{l}\text { Pengaruh inflasi terhadap } \\
\text { nilai uang } \\
\text { Risiko dan Diversifikasi } \\
\text { Saham }\end{array}$ & $\begin{array}{l}\text { Hastings et al. (2013), Lusardi \& } \\
\text { Mitchell (2014) dan Allgood (2016) }\end{array}$ \\
\hline $\begin{array}{l}\text { Faktor Demografi } \\
\qquad\left(\mathrm{X}_{2}\right)\end{array}$ & $\begin{array}{l}\mathrm{X}_{2.1} \\
\mathrm{X}_{2.2} \\
\mathrm{X}_{2.3}\end{array}$ & $\begin{array}{l}\text { Tahun Masuk Mahasiswa } \\
\text { kuliah } \\
\text { Pendapatan } \\
\text { Indeks Prestasi Kumulatif }\end{array}$ & $\begin{array}{l}\text { Margaretha, (2015), de Bassa } \\
\text { Scheresberg, (2013) Mahdzan, N.S. } \\
\text { (2013), Allgood (2016), }\end{array}$ \\
\hline \multirow[t]{2}{*}{$\begin{array}{l}\text { Minat Investasi } \\
\text { Mahasiswa }\left(\mathrm{Y}_{1}\right)\end{array}$} & $\mathrm{Y}_{1.2}$ & $\begin{array}{l}\text { Memiliki investasi pada } \\
\text { aset berharga }\end{array}$ & \\
\hline & $\begin{array}{l}\mathrm{Y}_{1.2} \\
\mathrm{Y}_{1.3}\end{array}$ & $\begin{array}{l}\text { Menyisihkan uang untuk } \\
\text { menabung } \\
\text { Membuat perencanaan } \\
\text { keuangan untuk masa } \\
\text { depan }\end{array}$ & $\begin{array}{l}\text { Allgood (2016), de Bassa Scheresberg, } \\
\text { Carlo (2013), Kholilah dan Iramani, } \\
\text { (2013) }\end{array}$ \\
\hline
\end{tabular}

\section{HASIL DAN PEMBAHASAN}

\section{Uji Validitas dan Reliabilitas}

Berdasarkan hasil uji validitas dan reliabilitas instrument pertanyaan pada penelitian ini yang diolah menggunakan program SPSS 20 didapatkan bahwa variabel literasi keuangan, faktor demografi dan minat investasi mahasiswa dinyatakan valid dan reliabel. Hasil tersebut dapat dilihat pada nilai signifikansi pada ketiga variabel $<5 \%$ sehingga semua variabel dinyatakan valid. Kemudian untuk uji reliabilitasnya ditunjukkan pada nilai cronbach alpha pada variabel literasi keuangan $\left(\mathrm{X}_{1}\right)$ sebesar 0,739 , variabel faktor demografi $\left(\mathrm{X}_{2}\right)$ sebesar 0,638 dan variabel minat investasi mahasiswa $\left(X_{3}\right)$ sebesar 0,696. Nilai tersebut dinyatakan reliabel karena berada di atas angka 0,6.

\section{Hasil Regresi}

Tabel 2

Model Summary

\begin{tabular}{lccc}
\hline Model & $\mathrm{R} \quad$ R Square & Adjusted R Square & $\begin{array}{c}\text { Std. An error of the } \\
\text { Estimate }\end{array}$ \\
\hline $1 \quad .861^{\mathrm{a}}$ & .741 & .735 & .795 \\
\hline a. Predictors: (Constant), X2, X1 & & \\
Sumber : Data primer yang diolah
\end{tabular}

Pada tabel 2 nilai Adjusted R Square adalah sebesar 0,735 atau 73\%. Nilai tersebut mendekati angka 1 sehingga bisa dikatakan bahwa variabel Literasi Keuangan $\left(\mathrm{X}_{1}\right)$ dan Faktor Demografik $\left(\mathrm{X}_{2}\right)$ memiliki sumbangan pengaruh yang 
kuat terhadap variabel Minat Investasi Mahasiswa $\left(\mathrm{Y}_{1}\right)$ sebesar $73 \%$ dan sisanya $27 \%$ dipengaruhi oeh variabel lainnya.

Tabel 3

Coefficients $^{\mathrm{a}}$

\begin{tabular}{|c|c|c|c|c|c|c|}
\hline \multirow{2}{*}{\multicolumn{2}{|c|}{ Model }} & \multicolumn{2}{|c|}{ Unstandardized Coefficients } & \multirow{2}{*}{$\frac{\text { Standardized Coefficients }}{\text { Beta }}$} & \multirow{2}{*}{$\mathbf{t}$} & \multirow{2}{*}{ Sig. } \\
\hline & & $\mathbf{B}$ & Std. Error & & & \\
\hline & (Constant) & .039 & .827 & & .047 & .962 \\
\hline \multirow[t]{2}{*}{1} & $\mathrm{X}_{1}$ & .639 & .097 & .574 & 6.560 & .000 \\
\hline & $\mathrm{X}_{2}$ & .358 & .094 & .334 & 3.817 & .000 \\
\hline
\end{tabular}

a. Dependent Variable: $\mathrm{Y}_{1}$

Pada Tabel 3 di atas dapat dilihat hasih regresi dari pengaruh variabel Literasi Keuangan $\left(\mathrm{X}_{1}\right)$ terhadap Minat Investasi Mahasiswa $\left(\mathrm{Y}_{1}\right)$ adalah positif signifikan. Hal ini ditunjukkan dari nilai t pada variabel $\mathrm{X} 1$ bernilai positif yaitu sebesar 6.560 dan nilai sig $0.000<0,05$ sehingga Hipotesis 1 diterima dan dapat diartikan bahwa literasi keuangan yang semakin baik akan diikuti pula dengan naiknya minat investasi mahasiswa begitupun sebaliknya apabila literasi keuangan yang dimiliki mahasiswa rendah maka minat investasinya juga akan turun.

Hasil yang sama untuk pengaruh dari variabel Faktor Demografik $\left(\mathrm{X}_{2}\right)$ terhadap Minat Investasi Mahasiswa $\left(\mathrm{Y}_{1}\right)$ dimana nilai t pada variabel $\mathrm{X}_{2}$ bernilai positif yaitu sebesar 3.817 dan nilai sig $0.000<0,05$ sehingga Hipotesis 2 pada penelitian ini diterima dan dapat diartikan bahwa Faktor Demografi $\left(\mathrm{X}_{2}\right)$ yang semakin tinggi akan diikuti pula dengan tingginya minat investasi mahasiswa begitupun sebaliknya apabila Faktor Demografi yang dimiliki mahasiswa rendah maka minat investasinya juga turun.

\begin{tabular}{|c|c|c|c|c|}
\hline \multicolumn{5}{|c|}{$\begin{array}{c}\text { Tabel } 4 \\
\text { ANOVA }^{a}\end{array}$} \\
\hline Model & Sum of Squares & $\begin{array}{cc}\text { Mf } & \begin{array}{c}\text { Mean } \\
\text { Square }\end{array}\end{array}$ & $\mathbf{F}$ & Sig. \\
\hline Regression & 157.054 & 278.527 & 124.337 & $.000^{\mathrm{b}}$ \\
\hline 1 Residual & 54.946 & .632 & & \\
\hline Total & 212.000 & 89 & & \\
\hline
\end{tabular}

Pada Tabel 4 di atas adalah hasil regresi secara simultan dari variabel Literasi Keuangan $\left(\mathrm{X}_{1}\right)$ dan Faktor Demografik $\left(\mathrm{X}_{2}\right)$ terhadap Minat Investasi Mahasiswa $\left(\mathrm{Y}_{1}\right)$ yang ditunjukkan pada hasil output tabel ANOVA dimana nilai F sebesar 124.337 dengan nilai sig adalah sebesar 0,000 di bawah taraf signifikansi yang diterapkan yaitu 0,05. Hasil ini menunjukkan bahwa hipotesis 
ketiga dari penelitian ini diterima dan dapat diartikan bahwa variabel Literasi Keuangan $\left(\mathrm{X}_{1}\right)$ dan Faktor Demografik $\left(\mathrm{X}_{2}\right)$ secara bersama-sama mempengaruhi variabel Minat Investasi Mahasiswa $\left(\mathrm{Y}_{1}\right)$ secara positif signifikan.

\section{E. HASIL \& PEMBAHASAN}

\section{Pengaruh Literasi Keuangan terhadap Minat Investasi Mahasiswa}

Hasil penelitian di atas pada tabel 3 menunjukkan bahwa Hipotesis 1 pada penelitian ini diterima yaitu bahwa literasi keuangan berpengaruh positif signifikan terhadap minat investasi mahasiswa di Fakultas Ekonomi dan Bisnis Universitas Muria Kudus. Hasil tersebut sesuai dengan hasil penelitian terdahulu yang telah dilakukan oleh Grohmann (2018) dan Humaira dan Sagoro (2018) yang menyatakan bahwa tingkat literasi keuangan yang lebih tinggi mempengaruhi pengambilan keputusan keuangan yang lebih baik. Hasil tersebut juga didukung oleh penelitian Lusardi, A., \& Mitchell, O. (2011), Putri \& Rahyuda (2017), Wibowo dan Purwahandoko (2019) yang menemukan adanya pengaruh positif dari literasi keuangan terhadap minat investasi seseorang. Pada penelitian ini dapat disimpulkan bahwa mahasiswa Fakultas Ekonomi dan Bisnis pada Universitas Muria Kudus yang sudah mempunyai pengetahuan tentang manajemen keuangan yang baik memiliki minat untuk melakukan investasi dan sebaliknya bagi mahasiswa yang kurang memiliki literasi keuangan tidak begitu berminat untuk melakukan investasi. Peran perguruan tinggi terutama untuk para dosen sangat penting dalam mengajarkan literasi keuangan kepada para mahasiswa di dalam proses perkuliahan. Hal ini perlu dilakukan agar mahasiswa dapat mengerti dan memahami secara benar tentang literasi keuangan dan pentingnya berinvestasi sejak dini. Pengetahuan keuangan yang dimiliki oleh mahasiswa saat kuliah inilah nantinya yang dapat menjadi bekal untuk mereka dapat mengelola investasinya dengan baik dan tepat.

\section{Pengaruh Faktor Demografi terhadap Minat Investasi Mahasiswa}

Hasil penelitian di atas pada tabel 3 menunjukkan bahwa Hipotesis 2 pada penelitian ini juga diterima yaitu bahwa faktor demografi berpengaruh positif signifikan terhadap minat investasi mahasiswa di Fakultas Ekonomi dan Bisnis Universitas Muria Kudus. Hasil ini sesuai dengan hasil penelitian Shaari et al (2013), Mahdzan, N.S., Tabiani, S. (2013), Allgood, (2016) dan Rizaldi dan Asandimitra (2019) yang menemukan bahwa faktor demografi juga ikut mempengaruhi minat investasi seseorang. Faktor demografi dalam penelitian ini diukur menggunakan beberapa indikator yaitu tahun masuk mahasiswa untuk kuliah, pendapatan dan nilai indeks prestasi (IPK) dari mahasiswa. Berdasarkan dari hasil penitian ini maka dapat dikatakan bahwa mahasiswa senior memiliki literasi keuangan yang lebih baik dibandingkan mahasiswa yunior yang baru masuk kuliah. Hal ini disebabkan karena mahasiswa semester atas otomatis sudah menerima mata kuliah tentang keuangan yang menambah pemahaman mereka terhadap literasi keuangan sehingga lebih berminat untuk berinvestasi. 
Pendapatan mahasiswa disini dapat diperoleh dari hasil mereka bekerja secara part time sambil kuliah atau dari uang saku yang diberikan oleh orang tua mereka. Indikator pendapatan ini juga berperan dalam meningkatkan minat investasi mahasiswa dikarenakan untuk investasi dibutuhkan dana yang tidak terpakai atau menganggur (idle fund) untuk bisa ditanamkan beberapa tahun kedepan dan tidak bisa digunakan secara cepat oleh mahasiswa. Sehingga semakin besar pendapatan yang diperoleh mahasiswa maka minat investasinya juga akan semakin meningkat. Hasil ini sesuai dengan hasil penelitian Malik (2017), Yusnita dan Abdi (2018), Rizaldi dan Asandimitra (2019) yang menemukan bahwa investor akan menaikkan jumlah investasi sahamnya berdasarkan adanya kenaikan pendapatan yang mereka terima. Selain pendapatan, nilai akademik mahasiswa yang tergambar dari nilai indeks prestasi kumulatif (IPK) juga berperan dalam menaikkan minat investasi. Hal ini disebabkan semakin pintar seseorang dalam memahami literasi keuangan yang telah diberikan oleh dosennya juga akan mempengaruhi minat mereka untuk berinvestasi. Hasil penelitian ini sesuai dengan hasil penelitian terdahulu oleh Irman (2018), Rizaldi dan Asandimitra (2019) yang menemukan bahwa IPK mahasiswa memiliki pengaruh yang positif terhadap tingkat literasi keuangan yang dimilikinya sehingga dapat meningkatkan minat mahasiswa untuk berinvestasi.

\section{F. SIMPULAN}

Berdasarkan hasil penelitian yang telah dijelaskan di atas, maka dapat diperoleh kesimpulan bahwa literasi keuangan dapat mempengaruhi minat investasi mahasiswa secara positif signifikan. Selain itu faktor demografi juga berpengaruh positif signifikan terhadap minat investasi mahasiswa di Fakultas Ekonomi dan Bisnis pada Universitas Muria Kudus. Hal ini menunjukkan bahwa mahasiswa yang memiliki kecerdasan akademik yang baik selama kuliah dengan diikuti adanya pendapatan yang dimiliki akan dapat meningkatkan minat investasi mereka. Dari sini dapat disimpulkan bahwa pendidikan tentang literasi keuangan pada perguruan tinggi sangat berperan penting untuk dapat meningkatkan minat investasi mahasiswa. 


\section{DAFTAR PUSTAKA}

Allgood, S., \& Walstad, W. B. (2016). The Effects Of Perceived And Actual Financial Literacy On Financial Behaviors. Economic Inquiry, 54(1), 675697. Https://Doi.Org/10.1111/Ecin.12255

Bhushan, P., \& Medury, Y. (2013). Financial literacy and its determinants. International Journal of Engineering, Business and Enterprise Applications (IJEBEA), 4(2), 155-160.

Chen, H., \& Volpe, R. P. (1998). An analysis of financial literacy among college students. Financial Services Review, 7(1), 107-128

Cheung, W. M., Chung, R., \& Fung, S. (2015). The Effects Of Stock Liquidity On Firm Value And Corporate Governance: Endogeneity And The REIT Experiment. Journal of Corporate Finance, 35, 211-231. Https://Doi.Org/10.1016/J.Jcorpfin.2015.09.001

Chen, H., Volpe, R.P. (1998), „An Analysis of Personal Financial Literacy among College Students", Financial Services Review, Vol. 7, No 2, pp.107-128.

Cude, B. J., Lawrence F. C., Lyons A. C., Metzger,K., LeJeune, E., Marks, L., \& Machtmes, K. (2006), College students and financial literacy: What they know and what we need to learn. Eastern Family Economics and Resource Management Association 2006 Conference

David L. REMUND. (2010). Financial Literacy Explicated: The Case For A Clearer Definition In An Increasingly Complex Economy. Journal Of Consumer Affairs, 44(2), 276-295. Https://Doi.Org/10.1111/J.17456606.2010.01169.X

Farooq, Aisha dan Sajid, Muhammad (2015). Factors Affecting Investment Decision Making: Evidence from Equity Fund Managers and Individual Investors in Pakistan. Research Jurnal of Finance and Accounting ISSN 2222-1697 (Paper) ISSN 2222 - 2847 (Online) Vol. 6, No. 9, Hal 135 - 141

De Bassa Scheresberg, C. (2013). Financial Literacy And Financial Behavior Among Young Adults: Evidence And Implications. Numeracy, 6(2). Https://Doi.Org/10.5038/1936-4660.6.2.5

Grohmann, A. (2018). Financial literacy and financial behavior: Evidence from the emerging Asian middle class. Pacific Basin Finance Journal, 48(July 2017), 129-143. https://doi.org/10.1016/j.pacfin.2018.01.007

Hassan Al-Tamimi, H. A., \& Anood Bin Kalli, A. (2009). Financial Literacy And Investment Decisions Of UAE Investors. Journal Of Risk Finance, 10(5), 500-516. Https://Doi.Org/10.1108/15265940911001402

Hastings, J. S., B. Madrian, and W. L. Skimmyhorn. "Financial Literacy, Financial Education and Economic Outcomes." Annual Review of Economics, 5, 2013, 347-73

Herdjiono, I., Damanik, L. A., \& Musamus, U. (2016). Pengaruuh Financial 
Attitude, Financial Knowledge, Parental Income Terhadap Financial Management, Jurnal Manajemen Teori dan Terapan Tahun 9. No. 3, Desember 2016 (3), 226-241.

Hogarth, J.M. (2002), „Financial Literacy and Family and Consumer Sciences”, Journal of Family and Consumer Sciences, Vol. 94, No 1, pp.15-28

Humaira, Iklima dan Sagoro, Endra M. 2018. Pengaruh Pengetahuan Keuangan, Sikap Keuangan dan Kepribadian terhadap Perilaku Manajemen Keuangan pada Pelaku UMKM Sentra Kerajinan Batik Kabupaten Bantul. Jurnal Nominal. Vol VII Nomor 1 Tahun 2018

Irman, Mimelientesa. 2018. Analysis Of Factors Affecting Financial Literacy Among University Students Muhammadiyah Riau (Umri) Pekanbaru. Journal of Economic, Business and Accounting (COSTING) Volume 1 $\begin{array}{lllll}\text { Nomor } & 2, & \text { Juni } & 2018 & \text { e-ISSN: }\end{array}$ https://doi.org/10.31539/costing.v1i2.205

Kholilah, Naila Al Dan Iramani, Rr. 2013. Studi Financial Management Behavior Pada Masyarakat Surabaya. Journal Of Business And Banking Vol. 3 No 1, Mei

Lusardi, A., \& Mitchell, O. S. (2011). Financial Literacy Around The World: An Overview. Journal Of Pension Economics And Finance, 10(4), 497-508. Https://Doi.Org/10.1017/S1474747211000448

Mahdzan, N. S., \& Tabiani, S. (2013). The Impact Of Financial Literacy On Individual Saving: An Exploratory Study In The Malaysian Context. Transformations In Business And Economics, 12(1), 41-55. Https://Doi.Org/10.1111/Jlme.12312

Malik, A. D. (2017). Analisa Faktor - Faktor Yang Mempengaruhi Minat Masyarakat Berinvestasi Di Pasar Modal Syariah Melalui Bursa Galeri Investasi UISI. Jurnal Ekonomi Dan Bisnis Islam, 3(1), 61-84

Margaretha, F., \& Pambudhi, R. A. (2015). Tingkat Literasi Keuangan Pada Mahasiswa S-1 Fakultas Ekonomi (Level Literacy Finance Student S-1 Faculty Of Economics). Jurnal Manajemen Dan Kewirausahaan, 17(1), 7685. Https://Doi.Org/10.9744/Jmk.17.1.76

Putra, I Putu Santika dkk. 2016. Pengaruh tingkat literasi keuangan, experienced regret, dan risk tolerance pada pemilihan jenis investasi. Journal of Business and Banking. Volume 5 Number 2 November 2015 - April 2016

Putri, Ni Made D.R., dan Rahyuda, Henny. 2017. Pengaruh Tingkat Financial Literacy dan Faktor Sosiodemografi terhadap Perilaku Keputusan Investasi Individu. E-jurnal Ekonomi dan Bisnis Universitas Udayana 6.9 (2017) : 3407-3434

Reddy, K., Locke, S., \& Scrimgeour, F. (2010). The Efficacy Of Principle-Based Corporate Governance Practices And Firm Financial Performance: An Empirical Investigation. International Journal Of Managerial Finance, 6(3), 
190-219. Https://Doi.Org/10.1108/17439131011056224

Rizaldi, Muhammad Hamzah dan Asandimitra, Nadia. 2019. Pengaruh Demografi, Pengalaman Bekerja, Dan Pendidikan Pengelolaan Keuangan Orang Tua Terhadap Literasi Keuangan Mahasiswa Di Perguruan Tinggi Surabaya. Jurnal Ilmu Manajemen Volume 7 Nomor 22019

Sabri, M. F., Othman, M. A., Masud, J., Paim, L., MacDonald, M., \& Hira, T. K. (2008). Financial Behavior And Problems Among College Studentsin Malaysia: Research and education implication. Consumer Interest Annual, 54, 166-170

Servon, L., \& Kaestner, R. (2008). Consumer Financial Literacy And The Impact Of Online Banking On The Financial Behavior Of Lower-Income Bank Customers. Journal of Consumers Affairs, 42(2), 271-305

Shaari, N. A., Hasan, N. A., Mohamed, R. K. M. H., \& Sabri, M. A. J. M. (2013). Financial literacy: A study among the university student. Interdisciplinary Journal of Contemporary Research in Business, 5(2), 279-299

Sugiyono. (2017). Metode Penelitian Bisnis. Bandung, Jawa Barat, Indonesia: Alfabeta.

Wibowo, Ari dan Purwohandoko. 2019. Pengaruh Pengetahuan Investasi, Kebijakan Modal Minimal Investasi, Dan Pelatihan Pasar Modal Terhadap Minat Investasi. Jurnal Ilmu Manajemen Volume 7 Nomor 12019

Widayati, Irin. 2012. Faktor-Faktor yang Mempengaruhi Literasi Finansial Mahasiswa Fakultas Ekonomi dan Bisnis Universitas Brawijaya. ASSET: Jurnal Akuntansi dan Pendidikan (1)

Yusnita, Raja R., dan Abdi, Muhammad. 2018. Pengaruh Faktor Demografi terhadap Literasi Keuangan. Journal of Economic, Business and Accounting (COSTING) Vol 2 Nomor 1, Juli-Desember 2018 